\title{
BMJ Open Pushing the limits of recovery in chronic stroke survivors: a descriptive qualitative study of users perceptions of the Queen Square Upper Limb Neurorehabilitation Programme
}

\author{
Kate Kelly, ${ }^{1}$ Fran Brander, ${ }^{1}$ Amanda Strawson, ${ }^{1}$ Nick Ward, ${ }^{1,2}$ Kathryn Hayward (i) ${ }^{3}$
}

To cite: Kelly K, Brander F, Strawson A, et al. Pushing the limits of recovery in chronic stroke survivors: a descriptive qualitative study of users perceptions of the Queen Square Upper Limb Neurorehabilitation Programme. BMJ Open 2020;10:e036481. doi:10.1136/ bmjopen-2019-036481

- Prepublication history for this paper is available online. To view these files, please visit the journal online (http://dx.doi org/10.1136/bmjopen-2019036481).

$\mathrm{KK}$ and $\mathrm{FB}$ are joint first authors.

Received 06 January 2020

Revised 22 July 2020

Accepted 21 August 2020

Check for updates

(C) Author(s) (or their employer(s)) 2020. Re-use permitted under CC BY-NC. No commercial re-use. See rights and permissions. Published by BMJ.

For numbered affiliations see end of article.

Correspondence to Professor Nick Ward; n.ward@ucl.ac.uk

\section{ABSTRACT}

Introduction The Queen Square Upper Limb (QSUL) Neurorehabilitation Programme is a clinical service within the National Health Service in the UK that provides 90-hours of therapy over 3-weeks to stroke survivors with persistent upper limb impairment. This study aimed to explore the perceptions of participants of this programme, including clinicians, stroke survivors and caregivers.

Design Descriptive qualitative. Data analysis was performed using a conventional thematic content approach to identify main themes by four researchers to avoid any potential bias or personal motivations, promoting confirmability.

Setting Clinical outpatient neurorehabilitation service. Participants Clinicians (physiotherapists, occupational therapists, rehabilitation assistants) involved in the delivery of the QSUL Programme, as well as stroke survivors and caregivers who had participated in the programme were purposively sampled. Each focus group followed a series of semi-structured, open questions that were tailored to the clinical or stroke group. One independent researcher facilitated all focus groups, which were audio-recorded and transcribed verbatim by a professional transcription agency.

Results Four focus groups were completed: three including stroke survivors $(n=16)$ and caregivers $(n=2)$, and one including clinicians $(n=11)$. The main stroke survivor themes related to psychosocial aspects of the programme ('you feel valued as an individual'), as well as the behavioural training provided ('gruelling, yet rewarding'). The main clinician themes also included psychosocial aspects of the programme ('patient driven ethos-no barriers, no rules') and knowledge, skills and resources of clinicians ('it is more than intensity, it is complex').

Conclusions As an intervention, stroke survivors and clinicians consider the QSUL Programme to be both comprehensive and complex. The nature of the interventions in the programme spans psychosocial and behavioural domains. We suggest the future clinical trials of upper limb rehabilitation consider testing the efficacy of these multiple interacting components.
Strengths and limitations of this study

- Descriptive qualitative study of the perception of users (stroke survivor, caregiver, clinician) engaged in the delivery of the Queen Square Upper Limb Neurorehabilitation Programme, which is run at a single centre in the UK.

- Focus groups were completed by a researcher independent of the programme, without the involvement of senior management to facilitate open discussion and critical reflection of the programme.

- This study involved a sample of users that were involved in the programme in the previous 12 months.

- Data coding was performed by four researchers enhancing the validity of the results.

- As only two caregivers were included in the focus groups, their experience has limited representation in the results.

\section{INTRODUCTION}

The burden of upper limb impairment after stroke remains high with up to $70 \%$ of survivors experiencing persistent difficulty using their affected upper limb 6-months poststroke. ${ }^{1-3}$ Recent clinical trials of treatments targeting the post-stroke upper limb have been underwhelming, possibly because the content of the treatment was ineffective or the dose was too low (13 to 36 hours total or 30 min per day). ${ }^{4-6}$ Two related trials in which 300 hours of upper limb therapy was delivered to chronic ( $>6$-months) stroke patients over 12-weeks were however strikingly positive. ${ }^{78}$ In line with this, several meta-analyses suggest that larger doses of therapy ( $>2$ hours per day) lead to clinically meaningful improvements of the upper limb post-stroke. ${ }^{9} 10$ The effective dose (measured in time) of neurorehabilitation is likely to be much higher than that tested in recent clinical trials. 
The Queen Square Upper Limb (QSUL) Neurorehabilitation Programme provided high dose, high intensity (90-hours over 3-weeks) neurorehabilitation for (mostly) chronic stroke survivors. ${ }^{11}$ Participants made improvements that are clinically meaningful and quantitatively similar to those reported by McCabe $e t a l l^{7}$ and Daly $e t$ $a l .^{8}$ Furthermore, the QSUL participants appeared to continue to improve after the programme (for up to 6 -months) although not at the same rate. In this service evaluation, we were therefore interested to explore the views of stroke survivors, caregivers and treating clinicians (physiotherapist, occupational therapist, rehabilitation assistant) on what the active ingredients of a successful upper limb rehabilitation programme, beyond high dose, might be. This information could be useful in defining the key components of a successful post-stroke upper limb intervention, which would benefit design of both clinical trials and clinical services.

\section{METHODS}

\section{Overview of design and methods}

A descriptive qualitative design was used. Focus groups with semi-structured, open questions and prompts were used to collect group perceptions and experiences. This study was registered with University College London Hospitals (UCLH) National Health Service Trust clinical audit and service development department as a service evaluation. All participants provided written informed consent to participate and for voice recording. All focus groups were completed in June 2017. This study is reported in accordance with the Consolidated criteria for Reporting Qualitative research (COREQ) checklist for interviews and focus groups ${ }^{12}$ and the Standards for Reporting Qualitative Research. ${ }^{13}$

We used purposive sampling to target participants who had completed the entire 3-week QSUL Programme plus 6-week and 6-month follow-up in the previous 12 months. To refine the sample targeted we used the following selection criteria: lived in/close to London and so were able to travel to attend the focus group face-to-face at the National Hospital for Neurology and Neurosurgery, Queen Square, London campus; diagnosis of stroke; and spoke English as their primary language. We excluded people with a diagnosis of traumatic brain injury or brain tumour, or severe aphasia preventing full participation in the focus group. Management and senior clinical staff working on the programme (KK, FB, AS) invited participants (either face-to-face, or by telephone or email contact) and their caregiver to participate in one of three focus groups. Staff attempted to contact participants twice by their preferred method identified on programme admission, after which they ceased attempting to contact the participant. Staff aimed to achieve sample variation in sex, age, time post-stroke, upper limb impairment (FuglMeyer assessment) and stage of programme follow-up. All clinicians who had been or were currently involved in delivery of the programme were invited to participate, including physiotherapists, occupational therapists and rehabilitation assistants. The managing clinical team members (KK, FB, NW) of the programme were not invited to participate to facilitate free sharing of perceptions by clinicians.

\section{Data collection}

All focus groups were performed in a quiet room within the hospital using a semi-structured question guide (table 1), which included main questions and prompts. The facilitator (KH, PhD, Research Fellow) was independent of the QSUL Programme, had not been part of any participant therapy or assessments and was not part of the managing clinical team. Her role was to encourage participants to share their personal experiences and opinions as to the key components of the programme (as a stroke survivor, caregiver or clinician) and used probing techniques and prompts to achieve further in-depth reflection. At the end of the focus group, the facilitator rephrased main experiences and meanings expressed to ensure accurate interpretation of participant views. Each focus group was audio-recorded and an additional independent person (final year physiotherapy placement student) took field notes during each focus group. The facilitator and field note personnel discussed each focus group at its end to corroborate main discussion points and notes.

\section{QSUL programme}

For a full description of the programme including staffing levels please see Ward et $a .^{11}{ }^{11}$ In brief, the QSUL Programme provides 90-hours of therapy over 3-weeks, with follow-up in an outpatient clinic at 6-weeks and 6 -months post programme completion. Two patients are admitted to the programme each week as day attendees (six patients are on the programme at one time), either from home or University College London Hospital dedicated patient hotel if they are self-caring, or self-caring with the support of one person. Daily intervention consists of 6-hours of scheduled therapy including two sessions each of one-on-one occupational therapy and physiotherapy focussed on analysis of movement and tasks, reduction of impairment and re-education of motor control within functional tasks. This is supplemented with two sessions of tailored individualised therapy with a rehabilitation assistant targeting repetitive task practice, sensory retraining, adjuncts to therapy such as functional splints, neuromuscular electrical stimulation, robotic devices and group work. Furthermore, patients are encouraged to work independently on cardiovascular fitness and are provided with homework to complete each weekend. Education, goal setting and developing self-efficacy for recovery are integral components that occur throughout the programme.

\section{Data analysis}

Baseline clinical measures were collected during participation in the QSUL Programme (see 11) and participant demographics were confirmed prior to the start of each 
Table 1 Focus group guide, including main questions and prompts

\section{Patients and caregivers}

Q1: Tell me about your experience of being involved in the day-to-day delivery of the QSUL Programme.

Probes:

How does this training programme differ to others?
What are your thoughts on the schedule?
What are some positive experiences?
What are some negative or challenging experiences?
Q2: How does this training programme impact recovery of
upper limb function (impairment/ activity/participation) post-
stroke?

Probes:

\begin{tabular}{|c|c|}
\hline Probes: & Probes: \\
\hline What about the training positively influenced recovery? & What about the training positively influences recovery? \\
\hline What about the training negatively influenced recovery? & What about the training negatively influences recovery? \\
\hline How could the programme be improved? & How could the programme be improved? \\
\hline Q3: What are the active ingredients of the programme? & Q3: What are the active ingredients of the programme? \\
\hline What aspects of the programme are essential? & What aspects of the programme are essential? \\
\hline What aspects are not essential/lower priority? Why? & What aspects are not essential/lower priority? Why? \\
\hline What about therapist skill set? Additional staffing & What about therapist skill set? Additional staffing \\
\hline $\begin{array}{l}\text { What about environment/resources/living/travel supports, } \\
\text { etc? }\end{array}$ & $\begin{array}{l}\text { What about environment/resources/living/travel supports, } \\
\text { etc? }\end{array}$ \\
\hline
\end{tabular}

QSUL, Queen Square Upper Limb Neurorehabilitation Programme. focus group. Verbatim transcription was performed by a professional transcription agency (K International, UK). A conventional thematic content approach was used. ${ }^{14} 15$ Four researchers performed data analysis to avoid any potential bias or personal motivations, promoting confirmability. First, researchers (KK, FB, AS, KH) independently read and became familiar with the complete data set. Second, researchers went through the transcripts line by line to obtain meaningful information and identify repeated topics and patterns. Researchers then interactively discussed interpretation of data to avoid bias in analysis, and integrated data into themes and subthemes. Credibility was enhanced through repeated discussions during the analysis process to (1) clarify interpretation of the data, (2) reframe key themes and subthemes confirming consistency of findings between researchers and (3) ensure that defined themes accurately reflected the expressions of the participants. Next, quotations and sections of text were extracted under thematic content and checked for consistency with the narrative theme. Finally, on two occasions two researchers (AS, KH) re-read all transcripts to confirm that all data fitted into the identified themes and subthemes: post completion of theme development and post manuscript write-up. During the writing stage, further refinement of links and subthemes occurred to ensure consistency of themes. All changes were discussed at each step between the four researchers

\section{Therapists}

Q1: Tell me about your experience of being involved in the day-

Probes:

How does this training programme differ to others?

What are some positive experiences? What are some negative or challenging experiences?

Who do you think benefits most from the programme? Why?

Q2: How does this training programme impact recovery of upper limb function (impairment/ activity/participation) poststroke?

What about the training negatively influences recovery? Have you found ways to get around/overcome these?

How could the programme be improved?

Probes:

What aspects of the programme are essential?

What aspects are not essential/lower priority? Why?

What about environment/resources/living/travel supports, to-day delivery of the QSUL Programme.

to achieve consensus. Final transcripts and results of the analysis were not discussed with participants.

\section{Patient and public involvement}

Patients and public were participants but were not involved in the design of this study.

\section{RESULTS}

\section{Stroke patients and caregivers}

From a purposive sample of 120 programme attendees during the previous 12-months, we invited 39 with a diagnosis of stroke living in/close by London to participate; two declined, 17 were unable to attend and four did not attend as planned. There were various reasons stroke survivors were unable to attend which included inability to take time off work, not wanting to travel into central London, away on holidays and inconvenient time of the focus group. Sixteen stroke survivors (eight male and eight female) and two caregivers (one male and one female) participated in one of three focus groups. See table 2 for stroke participant characteristics. The mean focus group duration was $79.7 \mathrm{~min}$.

\section{Overview of themes for stroke survivors and caregivers}

Two main themes, each containing subthemes, were identified from the transcripts and are presented in table 3 . 
Table 2 Demographics of stroke survivors, $n=16$

\section{Characteristic}

\begin{tabular}{|c|c|}
\hline Age, years, median (IQR) & 58 (48 to 69.3$)$ \\
\hline \multicolumn{2}{|l|}{ Sex } \\
\hline Female, n (\%) & $8(50)$ \\
\hline Male, n (\%) & $8(50)$ \\
\hline Months since stroke, median (IQR) & $19(12.5$ to 30.3$)$ \\
\hline \multicolumn{2}{|c|}{ Modified Fugl-Meyer upper limb*/54, median (IQR) } \\
\hline Programme entry (baseline) & 35 (23 to 43.5$)$ \\
\hline $\begin{array}{l}\text { Change during programme (baseline } 0 \\
\text { weeks to post } 3 \text { weeks) }\end{array}$ & 7 (2 to 8$)$ \\
\hline \multicolumn{2}{|l|}{ Paretic upper limb } \\
\hline Left, n (\%) & $12(75)$ \\
\hline Right, n (\%) & $4(25)$ \\
\hline \multicolumn{2}{|l|}{ Proportion dominant upper limb affected } \\
\hline Dominant, n (\%) & $7(43.75)$ \\
\hline Non-dominant, n (\%) & $9(56.25)$ \\
\hline $\begin{array}{l}\text { Family support available, self-reported, } n \\
(\%)\end{array}$ & $15(93.8)$ \\
\hline
\end{tabular}

Modes of QSUL programme access

\begin{tabular}{lc} 
Taxi vouchers, $\mathrm{n}(\%)$ & $5(31.3)$ \\
Hotel accommodation, $\mathrm{n}(\%)$ & $10(62.5)$ \\
Underground train, $\mathrm{n}(\%)$ & $1(6.3)$ \\
Employment status at QSUL Programme enrolment \\
Student, $\mathrm{n}(\%)$ & $2(12.5)$ \\
Retired, $\mathrm{n}(\%)$ & $5(31.3)$ \\
Not working, $\mathrm{n}(\%)$ & $4(25)$ \\
Working, $\mathrm{n}(\%)$ & $4(25)$ \\
Volunteering, $\mathrm{n}(\%)$ & $1(6.3)$ \\
\hline
\end{tabular}

*Modified Fugl-Meyer upper limb excludes measures of coordination and reflexes.

QSUL, Queen Square Upper Limb Neurorehabilitation Programme.

Theme 1: psychosocial - 'You feel valued as an individual' Stroke survivors and their caregivers consistently discussed the psychosocial components of the programme. Four subthemes were constructed from the data that were critical to enhancing participation during the 3-week

Table 3 Summary of themes identified from stroke survivor and caregiver focus groups

\begin{tabular}{ll}
\hline Main theme & Subthemes \\
\hline $\begin{array}{l}\text { Psychosocial - 'You feel valued as } \\
\text { an individual' }\end{array}$ & $\begin{array}{l}\text { Individualised goals } \\
\text { Motivation } \\
\text { Values and beliefs } \\
\text { Confidence }\end{array}$ \\
$\begin{array}{ll}\text { Behavioural Training - 'Gruelling, } \\
\text { yet rewarding' }\end{array}$ & $\begin{array}{l}\text { Pushing the limits } \\
\text { Opportunities to learn } \\
\text { Skill set and resources }\end{array}$ \\
\hline
\end{tabular}

programme, as well as maintaining motivation for recovery over the following 6-months of programme follow-up.

\section{Individualised goals}

Stroke survivors identified that the programme gave them the opportunity to set personalised goals collaboratively with an occupational therapist and physiotherapist, which impacted on their relationship with clinicians and engagement in the programme.

'Here's your thing - this is individualised, tailored to you, your needs, your goal.' (Stroke survivor).

Stroke survivors frequently discussed that they were encouraged to set ambitious and challenging goals with nothing considered off limits.

'You know you're going to take it in stages, you're going to build up to it but there's nothing - you don't get a no.' (Stroke survivor).

Stroke survivors highlighted that while most goals were focussed on their upper limb, they were encouraged to define goals related to their daily routine and/or leisure interests. A broader scope for defining goals meant that stroke survivors had the opportunity to experience the benefits of using their arm and hand more often in everyday situations.

'It was so good that you could bring in like your home life experiences, so it wasn't just doing things.' (Stroke survivor).

\section{Motivation}

Stroke survivors discussed how motivation to persist with the programme was drawn from a variety of sources. This included the enriched rehabilitation environment, variability of activities and incremental task progression throughout the programme. Additionally, the focus on meaningful real-world tasks was considered important to improve intrinsic motivation, and to maintain interest in working towards upper limb recovery.

'I found doing exercises all day very boring and difficult and not very motivating but when you're doing stuff that's actually fun and stimulating like playing tennis - it's doing the same stuff but you're having fun.' (Stroke survivor).

All stroke survivors discussed the high levels of support received throughout the programme, from both clinicians and fellow stroke survivors who may have had similar problems currently or in the past. The collaborative team focus of the programme, where stroke survivors and clinical staff are working in the same space, provided opportunities for enhanced motivation and self-efficacy; driven by observation-in-action.

'I didn't find any inhibitions when I came here. I didn't feel embarrassed once I was here with... with our little group.' (Stroke survivor). 
'When you work with a group you get some motivation as well because when you see the other people, they can do it, I can do it.' (Stroke survivor).

The impact of intrinsic motivation on achieved outcomes and recovery was discussed. Stroke survivors described observing some patients on the programme who had a lack of the 'right attitude', which was perceived to hinder recovery and potentially limit derived benefit from the programme.

'It's only going to work if you come with a positive attitude and you believe in yourself.' (Stroke survivor).

'I think after a while you adapt to your limitations and you don't try.' (Stroke survivor).

The structure of the programme along with the follow-up appointments, was described as integral to carry-over into the home environment. Knowing they were coming back for a follow-up appointment was considered to increase drive to continue with therapy after completing the programme.

'But you want to do it for them (clinicians) too because they've put a lot of work into helping you and you don't want to let them (clinicians) down.' (Stroke survivor).

\section{Values and beliefs}

Many of the participants reported feeling quite negative regarding their rehabilitation potential on discharge from previous therapy services or programmes. This created a nihilistic attitude towards recovery, as many patients were led to believe that they could not influence or drive their own progress.

'I was written off the year before but here it was 'no, we can work on that'...' (Stroke survivor).

The positive attitude of clinicians on the QSUL Programme was described as essential to help each individual acknowledge that they had the potential to improve their recovery, independently participate in the community and ultimately take ownership of their rehabilitation.

'...Puts you on the road - what to do to help yourself.' (Stroke survivor).

\section{Confidence}

All of the above subthemes were reported to have an extremely positive effect on the stroke survivors' confidence in their daily routine and activities, creating a sense of autonomy.

'After the 3-week programme I got some confidence for myself and now I can go around... getting involved in all activities, social media and everything... So it's both mentally and physically helpful.' (Stroke survivor).

Participants highlighted that being removed from their home environment, and their habitual routine and supportive families further enhanced their confidence in their own ability to be independent. Those that required use of programme access enablers, for example, using taxis or staying in the hotel, described these to positively influence independence and in turn, confidence.

'Managing my timing and getting up and sorting and getting to the breakfast room gave me a lot of confidence.' (Stroke survivor).

'I came here by myself - on the train and taxis and things like that, for me that was a big thing.' (Stroke survivor).

The well organised, positive team approach was considered important for building confidence for success. The opportunity to successfully achieve their goals by practice and repetition of tasks with feedback also contributed to confidence building.

'It's also what they offered, the team. The team made you feel positive and made you feel things were achievable.' (Stroke survivor).

\section{Theme 2: behavioural training - 'Gruelling, yet rewarding'}

The programme was described to provide the opportunity for stroke survivors to participate in gruelling, high-intensity behavioural training, which all stroke survivors reported that they relished. On completion of the programme, stroke survivors described that they had greater understanding of what their capabilities were, what was possible for the future and how to progress their training.

\section{Pushing the limits}

All stroke survivors acknowledged that the programme was exhausting, but the benefits of the intensity were superior. Some stroke survivors reported fatigue at the end of each day. Only one participant reported that it interfered with participation in the programme, which was able to be accommodated within the flexible structure of the programme.

'The harder they [clinicians] push the better the result and while it's gruelling, those that are happy to accept it... will know at the end of the day that they are going to be better.' (Stroke survivor).

'I mean I was that completely shattered and... by the end of the week I couldn't wait to stop the programme... I must confess, but I knew it was so, so helpful.' (Stroke survivor).

All stroke survivors agreed that having a structured timetable while on the programme was useful, giving them something to stick to, even when they may have felt like stopping. They felt the timetabling was tailored to the needs of the individual and was important to maintain a focus on therapy time, providing intensity and repetition of practice with variety. 
'The structure forces you to extend yourself and you need to be forced.' (Stroke survivor).

'I think it's important to keep a timetable. You can't slack off.' (Stroke survivor).

Critical to being able to push the limits were access enablers. For example, the close location of the hotel was considered by stroke survivors to minimise fatigue, and enable longer duration of active participation in the intense programme as distance barriers were removed.

\section{Opportunities to learn}

Tackling activities that were not able to be performed prior to attending the programme was important to participants. Trialling of new ideas to solve old problems was a unique experience, from which they learnt how to engage in behavioural training and real-world practice. Some participants described that the problemsolving skills and knowledge which they learnt on the programme had been carried over to help them solve new tasks when returning home. Many found the holistic approach and integration of physiotherapy and occupational therapy useful to learn new skills for overall recovery.

'If we couldn't do something one-way an alternative way was shown. I think it really came together because you could see how much you were learning.'

(Stroke survivor).

The opportunity to access gym equipment and aids for activities of daily living provided greater variety, as well as specificity within individual behavioural training. Stroke survivors reported the positive impact of extension of rehabilitation opportunities into the community when linked to their goals, for example, access to pushbikes, local gyms or swimming pools.

'Using the equipment, because I didn't think I would even try any equipment, but after I finished here I went and joined the local gym.' (Stroke survivor).

'They took me swimming and I played tennis and those were the two big things.' (Stroke survivor).

\section{Skill set and resources}

The stroke survivors stressed the importance of the skillset and expertise of the clinicians on the programme, as well as the collaborative relationships between clinicianpatient and physiotherapist-occupational therapist. The importance of integration of all skillsets and communication between all team members when delivering the service was considered to have a marked effect on the success of the programme.

'The fact that the course [programme] is physio and OT was so desperately important.' (Stroke survivor)

'I think it was a team effort...and between the two, the OT and the physiotherapist that you knew exactly what was going on.' (Stroke survivor).
Table 4 Demographics of clinicians, $n=11$

\begin{tabular}{ll}
\hline \multicolumn{2}{l}{ Characteristics } \\
\hline $\begin{array}{l}\text { Gender } \\
\text { Female, } \mathrm{n}(\%)\end{array}$ & $10(91)$ \\
\hline $\begin{array}{l}\text { Male, } \mathrm{n}(\%) \\
\text { Clinical profession }\end{array}$ & $1(9)$ \\
\hline $\begin{array}{l}\text { Occupational therapist, } \mathrm{n}(\%) \\
\text { Physiotherapist, } \mathrm{n}(\%)\end{array}$ & $4(36.4)$ \\
\hline $\begin{array}{l}\text { Rehabilitation assistant, } \mathrm{n}(\%) \\
\text { Therapist level }{ }^{\star} \text { and years of clinical practice }\end{array}$ & $2(18.5)$ \\
\hline $\begin{array}{l}\text { Highly specialist therapist, } \mathrm{n}(\%), \text { average } \\
\text { years of practice }\end{array}$ & $6(54.5), 11$ \\
\hline
\end{tabular}

Specialist therapist, $n(\%)$, average years of 3 (27.3), 6.3 practice

Rehabilitation assistant, n (\%), average years of practice

*'Highly specialist therapist' equates to an experienced therapist who has specialised in neurosciences for some years and is a team leader for the area in which they work. 'Specialist therapist' equates to a therapist who has specialised in neurosciences and is developing their skill set in this area, under leadership of the highly specialist therapist.

The skillset and creativity of the clinicians was considered essential to breakdown goals into achievable components, adapt techniques and adjust treatment modalities to allow goal practice.

'Therapists would say: 'Let's try a different way of either working with the problem or looking at the problem.' (Stroke survivor).

Stroke survivors perceived that small group sizes and a well-resourced environment was beneficial in supporting clinicians and important in programme success.

'Well they keep the groups fairly small... so they've actually got the time... so they can see each individual.' (Caregiver).

'You can't do the same thing unless you resource it in the same way.' (Stroke survivor).

\section{Clinicians}

Eleven clinicians (1 male and 10 female) participated in one focus group. One invited clinician was unavailable at the time of the focus group (highly specialist physiotherapist). See table 4 for characteristics of included clinicians. The focus group duration was $73.1 \mathrm{~min}$.

\section{Overview of themes for clinicians}

Two main themes, each containing subthemes, were identified and are presented in table 5 .

Theme 1: psychosocial

Goal setting

Clinicians highlighted the importance of individualised collaborative goal setting with stroke survivors. Some 
Table 5 Summary of themes identified from clinician focus group

\begin{tabular}{ll}
\hline Main theme & Subthemes \\
\hline $\begin{array}{l}\text { Psychosocial - 'Patient driven } \\
\text { ethos - no barriers, no rules' }\end{array}$ & $\begin{array}{l}\text { Goal setting } \\
\text { Confidence and } \\
\text { independence } \\
\text { Attitudes and ethos }\end{array}$ \\
$\begin{array}{ll}\text { Knowledge, skills and } \\
\text { resources - 'It is more than } \\
\text { intensity, it is complex' }\end{array}$ & $\begin{array}{l}\text { Skilled, integrated therapy } \\
\text { Education about stroke } \\
\text { recovery }\end{array}$ \\
\hline
\end{tabular}

mentioned the difficulties of setting functional goals when stroke survivors had very little movement and/or had achieved little recovery to date. Within the focus group, clinicians highlighted that they had the time to access a variety of resources as useful tools for developing stroke survivor engagement in their recovery and goal attainment.

'We have the time and the resources to focus thoroughly on what is a really key player in daily life and we all know that the upper limb is missed...'

A strategy described by many clinicians to support goalachievement was education about functional task practice or activities rather than impairment-based goals. Previous clinical experience and knowledge of goal setting processes was considered essential.

'Because we give them license to be quite creative and to be a bit aspirational and you can actually do goals that are really, really specific to the patient.'

\section{Confidence and independence}

The clinicians acknowledged that some of the gains made by stroke survivors during the programme related to improved confidence; not only in the ability to use their arm in tasks, but also in trying new tasks or skills, and persevering if they were not immediately successful. Clinicians perceived that stroke survivors also became more confident to participate in community tasks, leisure interests and in their ability to look after themselves, enhancing self-worth and identity.

'Surprised at how low and little confidence patients have. Also, how that confidence increases during the 3-weeks. I think it's a nice safe place for patients to try out different things.'

'I think it's good for some of the patients that aren't given much independence at home when their partners are not with them and they are encouraged to be more independent and do things by themselves.'

In addition, clinicians highlighted the support among the stroke survivors. Each group of stroke survivors became close-knit, encouraging and motivating each other during the programme, aiding with confidence building.
'I think there's a lot of camaraderie between them as well. I think they get a lot from each other and I think being staggered helps people to see each other on their own journey.'

\section{Attitudes and ethos}

Clinicians described the burden of high expectations from stroke survivors and programme management to deliver an intense programme with successful outcomes.

'I mean they've been told in clinic what they'll be getting and they've been told they've got potential to get better.'

Clinicians felt the ethos of the programme promoted a very open culture, allowing time and freedom to be creative around therapeutic and behavioural interventions. Many clinicians felt that anything was permitted on the programme and there were no barriers or rules to be broken.

'The whole culture and attitude is very much there's nothing you can't do which I think is really lovely.'

'I have never been able to take patients swimming, patients to a tennis court before.'

Clinicians acknowledged that there might be a positive bias in terms of the type of patient on the programme, in that stroke survivors had often actively sought referral to the clinic meaning that on the whole they had a drive to improve and willingness to learn. Clinicians also suggested that stroke survivors have to buy into the ethos of the programme, understanding and subscribing into the recovery process in order for it to be effective.

'I kind of feel like you've got them at the right time and the people that are being referred are clearly the ones seeking out further rehab so they are the ones that are motivated.'

The clinicians highlighted that there was a subset of stroke survivors that required more support and demonstrated increased reliance on clinicians, with less understanding and buy-in to the self-management aspect of the programme.

'The ones that get the most out of the programme are the ones that do take up the independent time to carry on something you've set up. More chance of carrying it over.'

Clinicians identified that stroke survivors' outcomes from the programme were not just due to intensity of hands-on therapy, behavioural training and ability to build on training day after day, but rather the ethos of the programme along with the holistic, integrated approach and multidisciplinary nature of the programme. It was more than just repetitions of movements.

'It's not intensity by itself, it's intensity of everything we've talked about - impairment, function, education, goals, independent tasks, homework, groups....' 
Theme 2: knowledge and skills

Skilled, integrated therapy

An important aspect of the programme that enabled smooth running was the skill and level of staffing. It was emphasised that the skillset was integral to implement a structured, yet flexible timetable to meet the varied needs of each stroke survivor. Many clinicians thought it was crucial to have previous neurological rehabilitation experience if you were to be a clinician on the programme, resulting in highly skilled clinical expertise and reasoning.

'The therapist's skill and knowledge base is the really crucial thing - like handling and creative problem solving.'

The clinicians understood each discipline's unique skillset and role, which enhanced their ability to work collaboratively. They highlighted the interdisciplinary working and holistic approach and the impact this had on stroke survivor outcomes. Teamwork and open communication were identified as essential to enable clinicians to learn from and support each other, enhancing their own skillset.

'It's not just physios working on impairment and OT's looking at function, it's really integrated which is really good.'

\section{Education about stroke recovery}

A key component of the programme described was education, both for the stroke survivors and their caregivers. The clinicians identified that a significant amount of time was spent throughout the programme educating stroke survivors about stroke, their upper limb and how to improve. This was done through impairment-based training, retraining quality of movement while performing daily activities and practising goals in real-world environments.

'You're not getting people in 3-weeks to change there and then but it's getting them to see how change can happen for years and years. Education is the foundation, so they go home and continue.'

Education was also described as useful to overcome barriers to buy-in. Some were described as more difficult to overcome including fatigue, cognitive deficits and negative health beliefs.

'I don't think they always come in with the best.... understanding of why they can't use their arm so there's a lot of - we talk a lot during sessions.'

\section{DISCUSSION}

Developing and implementing an intervention requires that the key components are properly defined and the context in which they are delivered is understood. ${ }^{16}$ Many trials of interventions aimed at promoting upper limb recovery have been unsuccessful or else the evidence is of relatively poor quality. ${ }^{17}$ Our aim here was to broaden the discussion about what the key components of poststroke upper limb intervention might be by investigating the stroke survivor, caregiver and clinician perceptions of a successful upper limb rehabilitation programme. We identified multiple behavioural and psychosocial aspects of the QSUL Programme that were considered important. Not surprisingly, there were overlapping themes; both the stroke survivor/caregiver and clinician groups considered the psychosocial aspects of the programme equally important as the behavioural training and intensity. Psychosocial and behavioural training includes individualised goal setting; building confidence and independence; attitudes and ethos; skilled, integrated therapy; and education about stroke recovery. The skilled, integrated therapeutic approach enabled experimentation of practice in order to achieve success in their individualised goals, sustaining motivation, ${ }^{18}$ improving confidence and self-efficacy. ${ }^{19}$ One interesting aspect of the QSUL Programme was the consideration from both interview groups that education about how to continue with stroke recovery was a vital component to sustain clinical improvements beyond the structured clinical rehabilitation environment.

Our results suggest that the successful QSUL Programme is a complex intervention, meaning it comprises multiple interacting components. However, we have not compared different interventions here and so we cannot conclude that the multiple behavioural and psychosocial components of QSUL are all necessary for the intervention to be successful. The value of this work is that it allows us to generate hypotheses about key components of upper limb rehabilitation that can then be tested in prospective clinical trials. For example, we might hypothesise that the educational component (about ongoing stroke recovery) is necessary to achieve sustained improvement after the 3-week programme; or that psychosocial components will differentially affect participation compared with impairment.

It is useful to look at published clinical trials or descriptions of post-stroke upper limb rehabilitation to understand how they differ in terms of complexity. More complex upper limb therapy interventions, ${ }^{578}$ including QSUL, ${ }^{11}$ seem to have between 8 to 12 key components/ingredients (see table 6A). In contrast, the most commonly investigated interventional approaches, including constraint-induced movement therapy, repetitive task training and robotics, include far fewer components (see table 6B); with constraint-induced movement therapy being the only to one to include both behavioural (intensive therapy) and psychosocial methods (to enhance transfer to real-world environments). In the context of the current discussion, it is of interest to note that constraint-induced movement therapy is generally only effective if it includes both intensity of behavioural therapy and the transfer package ${ }^{20}$; simply constraining the unaffected limb is ineffective. ${ }^{20}$ Of the more complex approaches to upper limb rehabilitation, only iCARE was an adequately powered, multicentre, randomised 
Table 6 Components of upper limb stroke recovery treatments: (A) key components of interventions tested in individual studies and (B) components of interventions classes evaluated by systematic reviews

\section{A}

\section{QSUL, Ward et al ${ }^{11}$}

Eight components of the QSUL approach:

1. Initial assessment consisting of analysis of both movement and performance in activities of daily living.

2. Identification of aspirational, individualised goals. promoting re-education of motor control within activities of daily living.

\section{Individualised meaningful tasks practiced repeatedly in order to facilitate task mastery with a focus on quality of movement; achieved through (1) adaptation of the task; (2) adaptation of the environment; (3) assistance; and (4) independent task practice.}

\section{Daly et $a l^{8}$}

Twelve components defined by Daly et al, 2019 (replication of McCabe et al, 20157):

1. Classification of initial training level.

2. Awareness training of normal and abnormal movement patterns, which empowers and motivates the patient to self-monitor and selfprogress.

3. Training focussed on recovery of the coordination of isolated joint movements and multiple joint movements, with multiple treatment strategies employed to support practice of movement as close to normal as possible.
4. Titrated progression of treatment.

\section{iCARE, Winstein et $a^{\mathfrak{j}}$}

Eight principles defined iCARE protocol:

1. Ensure challenging and meaningful practice.

\section{Address important mutable} impairments.

3. Enhance motor capacity through overload and specificity.

4. Preserve natural goal-directedness in movement organisation.
5. Very finely incrementalised progression of treatment, using an array of methods to support motor practice as close to normal as possible, and attention (and celebration) to small goal achievement.

6. Clearly stated goals for each small incrementalised practice. planning and delivery via a mix of 1:1, group and technology sessions.

\section{Inclusion of sessions focussed beyond upper} limb motor practice, including sensory retraining, cardiovascular fitness, gait and balance training.

\section{Weekend homework to improve carryover to out} of clinic environments.

\section{Weekly meeting of clinical team.}

7. Incorporation of newly recovered joint movement coordination into task component practice.

8. Task and task component selection customised as much as possible to align with the interests and needs of each individual.

9. Engagement of as many strategies as necessary to obtain continued attention and high repetition practice of coordinated movements.

10. Observation and monitoring of inattention or fatigue, and with rest periods held in that case.

11. Weekly team meeting of clinical team in which obstacles to progression are described and problem-solving is offered by team members.

12. Periodic team-treatment, whereby another therapist visits the treatment sessions and offers observations and suggestions.

B Constraint induced movement therapy ${ }^{20}$ Original:

\section{Repetitive task training ${ }^{23}$}

1. Active motor sequence was performed repetitively within a single training session, and where the practice was aimed towards a clear functional goal.
5. Avoid artificial task breakdown when engaging in task-specific practice.

6. Active patient involvement and opportunities for self-direction are feasible and desirable.

7. Balance immediate and future needs for efficient motor skill and capacity enhancement with the development of confidence and self-management skills.

8. Drive task-specific self-confidence (self-efficacy) high through performance accomplishments. 
Table 6 Continued

1. Intensive, graded practice of the paretic upper limb to enhance task-specific use of the affected limb for up to 6-hours per day for 2-weeks (ie, shaping whereby patients are progressively trained for tasks that progressively increase in difficulty.

\section{Constraint or forced use therapy, with the non- paretic upper limb contained in a mitt to promote the use of the impaired limb during $90 \%$ of the total hours awake.}

3. Adherence-enhancing behavioural methods designed to transfer the gains obtained in the clinical setting or the laboratory to patients' real-world environment (ie, a transfer package).
2. Functional goals could involve complex whole tasks (eg, picking up a cup), or pretask movements for a whole limb or limb segment such as grasp, grip, or movement in a trajectory to facilitate an ADL-type activity (eg, sit-to-stand).

\section{Repetitive activity required to involve} complex multi-joint movement, rather than the exercise of a single joint or muscle group orientated to motor performance outcomes.

\section{a. Passively,}

Modified: This therapy does not include the three components of original CIMT, but is restricted to repetitive, task-specific training of the paretic arm, including shaping procedures, applied in a different dose, combined with constraining of the nonaffected hand by a padded mitt, glove or splint.

\section{d. Perform bimanual exercises.}

c. Assisting active movements of isolated joint or multiple segments to perform reaching-like movements, or

2. The progression of therapy with electromechanical devices is possible by varying the force, decreasing assistance, increasing resistance and expanding the movement amplitude.

ADL, activities of daily living; CIMT, Constraint Induced Movement Therapy; QSUL, Queen Square Upper Limb neurorehabilitation programme.

controlled trial. ${ }^{5}$ The iCARE trial, however, had a neutral outcome as the findings were likely confounded by the low dose (30-hours over 10-weeks). Consistent with the QSUL Programme, the iCARE intervention did have a focus on the psychosocial aspects of behavioural training including active patient involvement in goals and development of self-management skills. McCabe et $a l^{7}$ and Daly et $a l^{8}$ were both before-after clinical studies that demonstrated large, clinically meaningful results from an intensive training protocol (300-hours over 12-weeks) that included the most behavioural training ingredients. In these studies $^{78}$ of arguably the largest dose of rehabilitation tested to date, there was less focus on the psychosocial components such as individualised goal setting and education about stroke recovery. Yet they still saw large improvements both in terms of reducing impairment and improving activity, which were maintained at 3-months. ${ }^{8}$ Comparison of these three approaches ${ }^{5} 7811$ does not unambiguously point to the key components of successful upper limb rehabilitation. However, it does highlight a range of factors that need to be considered in planning future clinical trials. We argue that complexity in upper limb rehabilitation should be embraced using well defined methodologies ${ }^{21}$ and that determining the optimal combination of active ingredients simply by studying each in isolation is unlikely to be a successful strategy. A discussion of the methodological considerations for the next iteration of stroke recovery trials is contained elsewhere. ${ }^{16}$

\section{Strengths and limitations}

Each focus group was facilitated by an independent person not involved in any aspect of the programme. Focus groups were independently transcribed by an external source. Gaining the perspective of multiple users enabled corroboration and triangulation of data and themes. This study does however have a small sample size relative to the number of patients that have gone through the QSUL Programme $(\mathrm{n}>200),{ }^{11}$ as well as few male clinicians and limited perspectives of caregivers that were able, or chose to be in attendance at focus groups. In addition, the perspective of managers and decisionsmakers were not captured. We acknowledge that these views are important to explore prior to implementation of similar programmes in other clinical settings. Collectively, these limitations do impact generalisability. Finally, focus groups were completed (for some) months after participation in the programme, therefore recall bias may be an issue.

\section{CONCLUSION}

This study provides an interesting perspective of how an intensive upper limb neurorehabilitation programme is perceived by stroke survivors and clinicians involved. While the 'gruelling' intensity provided in this programme was considered important, creating individualised training opportunities that equip stroke survivors with skills, resources and knowledge to drive their own recovery for the longer-term was equally emphasised. These considerations are important in determining the content of an upper limb neurorehabilitation trial that more accurately reflects effective clinical practice. Tools such as TIDieR $^{22}$ (Template for Intervention Description and Replication) are key to defining the important components of a therapy programme and understanding the rationale for inclusion of each component and potential impact on recovery. 


\section{Author affiliations}

${ }^{1}$ University College London Hospitals NHS Foundation Trust National Hospital for Neurology and Neurosurgery, London, UK

${ }^{2}$ Department of Clinical and Motor Neuroscience, UCL Institute of Neurology, University College London, London, UK

${ }^{3}$ Department of Physiotherapy, Florey Institute of Neuroscience and Mental Health, and NHMRC CRE in Stroke Rehabilitation and Brain Recovery, The University of Melbourne, Melbourne, Victoria, Australia

Acknowledgements Thanks to all the physiotherapists and occupational therapists at The National Hospital for Neurology and Neurosurgery, Queen Square, who have treated patients on this programme. Thanks to all the patients who have taken part in the programme. Thanks to UCLH Charities, Friends of UCLH and The National Brain Appeal for funding to purchase equipment used in the programme. $\mathrm{KH}$ received fellowship support from the National Health and Medical Research Council (NHMRC) of Australia (GNT1088449) and Michael Smith Foundation for Health Research British Columbia Canada (15980). KH was also supported by a trainee travel award from the Canadian Partnership for Stroke Recovery, Future Leader Grant from the Stroke Foundation and Bayer Science and Education Foundation Award for Early Excellence in Science, which collectively supported her to undertake this collaborative research work. $\mathrm{KH}$ is employed by The Florey Institute of Neuroscience and Mental Health, who acknowledges the strong support from the Victorian Government and in particular funding from the Operational Infrastructure Support Grant.

Contributors KH, NW, KK and FB conceived the study. KH, KK, FB and AS developed the focus group guide, thematically analysed the focus groups and wrote the manuscript; all authors intellectually contributed, reviewed and edited the manuscript; KH led the focus groups, AS led participant recruitment.

Funding This work was supported by funds from the 0ccupational Therapy Research Fund, National Hospital for Neurology and Neurosurgery.

Competing interests None declared.

Patient and public involvement Patients and/or the public were not involved in the design, or conduct, or reporting, or dissemination plans of this research.

Patient consent for publication Not required.

Provenance and peer review Not commissioned; externally peer reviewed.

Data availability statement Data are available upon reasonable request to Drs Ward or Hayward from credible researcher.

Open access This is an open access article distributed in accordance with the Creative Commons Attribution Non Commercial (CC BY-NC 4.0) license, which permits others to distribute, remix, adapt, build upon this work non-commercially, and license their derivative works on different terms, provided the original work is properly cited, appropriate credit is given, any changes made indicated, and the use is non-commercial. See: http://creativecommons.org/licenses/by-nc/4.0/.

ORCID iD

Kathryn Hayward http://orcid.org/0000-0001-5240-3264

\section{REFERENCES}

1 Lawrence ES, Coshall C, Dundas R, et al. Estimates of the prevalence of acute stroke impairments and disability in a multiethnic population. Stroke 2001;32:1279-84.

2 Nakayama H, Jørgensen HS, Raaschou HO, et al. Recovery of upper extremity function in stroke patients: the Copenhagen stroke study. Arch Phys Med Rehabil 1994;75:394-8.
3 Persson HC, Parziali M, Danielsson A, et al. Outcome and upper extremity function within 72 hours after first occasion of stroke in an unselected population at a stroke unit. A part of the SALGOT study. BMC Neurol 2012;12:162.

4 Lang CE, Strube MJ, Bland MD, et al. Dose response of taskspecific upper limb training in people at least 6 months poststroke: a phase II, single-blind, randomized, controlled trial. Ann Neurol 2016;80:342-54.

5 Winstein CJ, Wolf SL, Dromerick AW, et al. Effect of a task-oriented rehabilitation program on upper extremity recovery following motor stroke: the ICARE randomized clinical trial. JAMA 2016;315:571-81.

6 Lo AC, Guarino PD, Richards LG, et al. Robot-assisted therapy for long-term upper-limb impairment after stroke. N Engl J Med 2010;362:1772-83.

7 McCabe J, Monkiewicz M, Holcomb J, et al. Comparison of robotics, functional electrical stimulation, and motor learning methods for treatment of persistent upper extremity dysfunction after stroke: a randomized controlled trial. Arch Phys Med Rehabil 2015;96:981-90.

8 Daly JJ, McCabe JP, Holcomb J, et al. Long-dose intensive therapy is necessary for strong, clinically significant, upper limb functional gains and retained gains in Severe/Moderate chronic stroke. Neurorehabil Neural Repair 2019;33:523-37.

9 Lohse KR, Lang CE, Boyd LA. Is more better? using metadata to explore dose-response relationships in stroke rehabilitation. Stroke 2014;45:2053-8.

10 Schneider EJ, Lannin NA, Ada L, et al. Increasing the amount of usual rehabilitation improves activity after stroke: a systematic review. J Physiother 2016;62:182-7.

11 Ward NS, Brander F, Kelly K. Intensive upper limb neurorehabilitation in chronic stroke: outcomes from the Queen square programme. $J$ Neurol Neurosurg Psychiatry 2019;90:498-506.

12 Tong A, Sainsbury P, Craig J. Consolidated criteria for reporting qualitative research (COREQ): a 32-item checklist for interviews and focus groups. Int J Qual Health Care 2007;19:349-57.

13 O'Brien BC, Harris IB, Beckman TJ, et al. Standards for reporting qualitative research: a synthesis of recommendations. Acad Med 2014;89:1245-51.

14 Green J, Thorogood N. Qualitative methods for health research. 2nd edn. London: SAGE Publications, 2009.

15 Hsieh H-F, Shannon SE. Three approaches to qualitative content analysis. Qual Health Res 2005;15:1277-88.

16 Bernhardt J, Hayward KS, Dancause N, et al. A stroke recovery trial development framework: consensus-based core recommendations from the second stroke recovery and rehabilitation roundtable. Int $J$ Stroke 2019;14:792-802.

17 Pollock A, Farmer SE, Brady MC, et al. Interventions for improving upper limb function after stroke. Cochrane Database Syst Rev 2014;23:CD010820.

18 Luker J, Lynch E, Bernhardsson S, et al. Stroke survivors' experiences of physical rehabilitation: a systematic review of qualitative studies. Arch Phys Med Rehabil 2015;96:1698-708.

19 Jones F, Riazi A. Self-efficacy and self-management after stroke: a systematic review. Disabil Rehabil 2011;33:797-810.

20 Kwakkel G, Veerbeek JM, van Wegen EEH, et al. Constraint-induced movement therapy after stroke. Lancet Neurol 2015;14:224-34.

21 Craig P, Dieppe P, Macintyre S, et al. Developing and evaluating complex interventions: the new medical research council guidance. BMJ 2008;337:a1655.

22 Hoffmann TC, Glasziou PP, Boutron I, et al. Better reporting of interventions: template for intervention description and replication (TIDieR) checklist and guide. BMJ 2014;348:91687.

23 French B, Thomas LH, Coupe J, et al. Repetitive task training for improving functional ability after stroke. Cochrane Database Syst Rev 2016;11:CD006073.

24 Mehrholz J, Hädrich A, Platz T, et al. Electromechanical and robotassisted arm training for improving generic activities of daily living, arm function, and arm muscle strength after stroke. Cochrane Database Syst Rev 2012;6:CD006876. 